\section{Job satisfaction among dually qualified dental hygienist- therapists in UK primary care: a structural model}

\author{
S. Turner, ${ }^{1}$ M. K. Ross ${ }^{2}$ and R. J. Ibbetson ${ }^{3}$
}

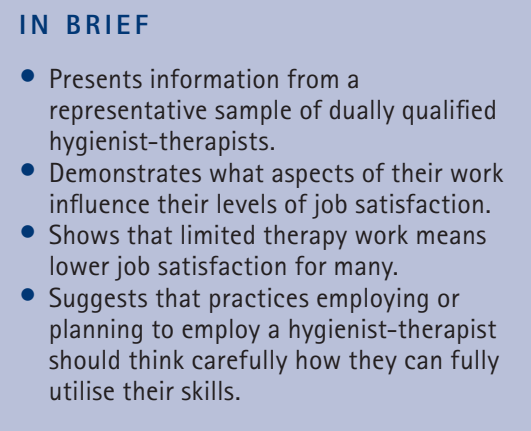

Objective To investigate job satisfaction among hygienist-therapists. Increasing numbers of hygienist-therapists work in UK primary dental care teams. Earlier studies suggest a clinical remit/clinical activity mismatch, without investigating any link with job satisfaction. Methods A UK-wide survey of dental hygienist-therapists using a random sample of the General Dental Council Register of Dental Care Professionals. Factors associated with job satisfaction (measured by the Warr-Cook-Wall ten-dimension scale) were entered into a series of multiple regression analyses to build up a path model. Results Analysis was undertaken on 183 respondents (response rate: 60\%). Mean score for overall satisfaction was 5.36 (SD 1.28) out of a range of 1-7. Multiple regression analysis confirmed the following direct predictors of overall job satisfaction: satisfaction with colleagues, remuneration, variety of work; rating of hygiene work as rewarding; and not being self-employed $\left(R^{2}=0.69\right)$. Satisfaction with variety of work was the strongest predictor, itself strongly predicted by the extent the clinical remit was undertaken. Dentists' recognition of their remit, quality of clinical work and qualifications had a strong indirect effect on overall job satisfaction. Conclusions The study suggests both greater use of the therapy skills these individuals possess, and better recognition of their remit, qualifications and quality of work by their dentist colleague, may be linked to higher job satisfaction. The implications for the policy of greater team working in dental primary care are discussed.

\section{INTRODUCTION}

In all fields of health care, need and demand are outstripping the capacity of the established professions to provide full, responsive and appropriate services, with due regard to the prevention of disease. This situation has highlighted the role of allied and complementary professionals in dentistry as in other health services. Changes to the dental contract in England and other UK Government initiatives have encouraged members of the dental team to re-examine the way they work and the evidence base for these ways of working. In general dental practice, clinically active members of the team include dentists, hygienists, therapists and, more recently, dually qualified hygienist-therapists.

Senior Researcher, ${ }^{2}$ Senior Lecturer for Dental Care Professionals, ${ }^{3}$ Director, Edinburgh Postgraduate Dental Institute, Level 4, Lauriston Building, Lauriston Place, Edinburgh, EH3 9HA

*Correspondence to: Steve Turner

Email:s.turner@cpse.dundee.ac.uk

\section{Refereed Paper}

Accepted 6 August 2010

DOI: 10.1038/sj.bdj.2011.50

${ }^{\circledR}$ British Dental Journal 2011
The dual qualification of dental hygienisttherapy was established in the UK in 1983, following the discontinuation of the dental therapy single qualification. Today most of the 19 UK training centres offer only the dual qualification (as opposed to the single dental hygiene qualification), and hygienist-therapists represent a rapidly growing proportion of the dental workforce both in independent general dental practice and in the salaried dental service. By April 2010 there were over 1,200 hygienist-therapists registered on the General Dental Council register of Dental Care Professionals (DCPs), with numbers increasing by approximately 10\% each year. Although most have completed a dual hygiene therapy course, some singly-qualified therapists and hygienists have subsequently taken a second course to obtain dual qualification. Such training brings a wide clinical remit, with the exceptions of procedures involving the adult pulp and the dental laboratory. There is a current legal requirement for referral from a dentist.

A number of UK studies have revealed potential problems in building a dental team to include these DCPs. Harris and Burnside found that dental therapists' duties varied considerably in a sample of four Personal Dental Service practices in England. ${ }^{1}$ A large-scale survey was conducted investigating dental therapists' clinical work undertaken in the UK. This study reported that therapists felt that their therapy skills were underused and this was reflected in the free text comments that were received from therapists on the impacts on pay, teamwork and their general satisfaction with the role they were performing. ${ }^{2}$ The present study builds upon these findings in order to identify the predictors of job satisfaction in therapists and hygienists.

Poor knowledge and negative attitudes of dentists and dental students may restrict the development of the dental team. ${ }^{3-5}$ Although earlier research suggests high levels of job satisfaction among singly qualified therapists, ${ }^{6,7}$ no studies have been conducted into the job satisfaction of dually qualified hygienist-therapists or how this might relate to their role in the dental team. ${ }^{8}$ In a recent study of UK 
National Health Service general nurses, job satisfaction was shown to be a key determinant of intention to leave. ${ }^{9}$

\section{MATERIALS AND METHODS}

The aim of this study is to identify predictors of job satisfaction of dually qualified hygienist-therapists working in UK primary dental care. The main hypothesis is that, given the reported underuse of therapists' and dually qualified hygienist-therapists' skills, ${ }^{8}$ job satisfaction is lower with such underuse. This paper focuses on dually qualified hygienist-therapists as they are the most rapidly expanding group of dental care professionals, they have the broadest clinical remit, and clearly represent the future of this type of dental care practice in the UK.

A random sample survey of hygienisttherapists (together with parallel samples of singly-qualified hygienists and therapists) was conducted across the UK. The General Dental Council (GDC) register of DCPs was used as the sampling frame, as all UK-based DCPs are required to register with the GDC before they can practise. A total of 821 hygienist-therapists were identified on the GDC register obtained in February 2009. Three hundred were randomly selected using an online random sample generator, stratified by country. The sample size was determined by assuming a response rate of $66 \%$ and an error rate of 5\% at 90\% confidence level, and followed external statistical advice.

A questionnaire was developed, piloted and distributed by post in April-May 2009. A reminder letter was sent out in May, followed by a second reminder and questionnaire in June 2009. Mailing procedure, questionnaire design, wording of questions, and content of cover letter and reminders followed recommended practice for health service-related surveys. ${ }^{10}$

The questionnaire covered the following areas: qualifications held and institution attended; current employment and caseload; the nature of referrals from dentists; clinical and treatment planning activities undertaken; nature and adequacy of training; soft tissue lesions; autonomous working; CPD activities; future changes to remit and referral; patient and dentist attitudes; and job satisfaction. These topics were chosen based on a review of the literature, including the authors' own research, and of current issues in dental primary care. For example, in early 2010 the GDC began a review of the requirement for a referral from a dentist before therapists and hygienists can undertake patient treatment.

Job satisfaction was measured by the Warr-Cook-Wall scale. While brief, it produces ratings of overall job satisfaction and satisfaction in nine domains, allowing examination of intrinsic (job content) and extrinsic (eg pay and conditions) satisfaction. Reliability and validity data have been reported..$^{11}$ The domains all appear to have good face validity with this sample. In particular, aspects of intrinsic job satisfaction (satisfaction with variety of work, amount of responsibility, and recognition of clinical activity) have been identified as potential issues in this group. ${ }^{8}$ Each aspect is rated on a seven-point scale ( 1 = extreme dissatisfaction, 7 = extreme satisfaction). The scale has been used in a number of studies and occupations, including UK primary care staff. For this sample a Chronbach alpha coefficient of 0.90 was obtained for the domain scores, indicating its reliability for use with this group. All analysis was conducted using SPSS v17. Paired samples t-tests were used to compare the nine domain scores with overall satisfaction scores.

This paper follows a path analysis approach to investigate direct and indirect predictors of overall job satisfaction. Path analysis is a straightforward extension of multiple regression analysis used to identify important influences on the outcome measure of interest. ${ }^{12}$ The method has the advantage of focusing not only on factors directly associated with the outcome, but also on those with important indirect associations with the outcome (that is, are strongly associated with a factor which itself is strongly associated with the outcome measure). This may assist in identifying potential areas of intervention. The value of any indirect path is found by multiplying together the beta weights (path partial coefficients).

While the Warr-Cook-Wall measure generates ordered categorical variables, Scott et $a l .{ }^{13}$ argue that it is accepted practice to treat the nine domain variables and the overall job satisfaction variable as continuous cardinal variables in path analysis models. The same authors also conclude that a model of overall job satisfaction which includes the domain scores in addition to job and personal characteristics performs better than alternatives that include only the job domains or that exclude them.

A review of the literature suggests that three categories of factors may influence overall job satisfaction:

1. Background measures of personal and work characteristics: gender, age, pressure at work (number of patients seen per session), hours worked, years in current post, self-employment, working in the Salaried Dental Service

2. Assessments of aspects of work: level of autonomy in 15 clinical activities, appraisal of hygienist activity (scale and polish and preventive work rated as rewarding), percentage of clinical remit undertaken (how often 19 treatments were undertaken), recognition by dentists and by patients (two separate 12-point rating scales of the recognition of therapists' clinical remit, quality of work, and qualification: Chronbach alphas of 0.79 (dentists) and 0.74 (patients))

3. The nine domains of the Warr-CookWall job satisfaction scale.

Descriptive statistics were used to check whether the measures of job satisfaction and other continuous variables were normally distributed. The satisfaction ratings and ratings of patient and dentist recognition were negatively skewed (ie ratings clustered towards the favourable end of the scale). Such a skew is common in job satisfaction ratings and was felt to be within acceptable limits. Finally, it is recommended that the number of independent variables in a multiple regression analysis should be no more than the number of cases $/ 10,{ }^{12}$ indicating that no more than 18 independent variables should be used in this analysis.

\section{RESULTS}

Of the 300 individuals mailed, 181 responded, giving an initial response rate of $60 \%$. This response gives an error rate of $5.4 \%$ at $90 \%$ confidence level. Seven respondents are excluded from this paper on the grounds that they were not currently working in public dental primary care (that is, were on disability leave, or 


\begin{tabular}{|c|c|c|c|c|c|}
\hline \multirow[t]{2}{*}{ Satisfaction domains (range) } & \multirow{2}{*}{$\begin{array}{l}\text { Mean } \\
\text { (SD) }\end{array}$} & \multirow{2}{*}{$\begin{array}{l}\text { Correlation } \\
\text { with overall } \\
\text { satisfaction } \\
\text { (sig. level) }\end{array}$} & \multicolumn{2}{|c|}{ Paired differences } & \multirow[t]{2}{*}{$\mathrm{N}$} \\
\hline & & & $\mathrm{t}$ & $\begin{array}{l}\text { Sig. level (95\% C.I. } \\
\text { of the difference) }\end{array}$ & \\
\hline $\begin{array}{l}\text { Colleagues and fellow workers } \\
(1-7)\end{array}$ & $\begin{array}{l}5.67 \\
(1.82)\end{array}$ & $0.61(0.001)$ & 3.79 & $0.000(0.15,0.47)$ & 182 \\
\hline $\begin{array}{l}\text { Physical working conditions } \\
(1-7)\end{array}$ & $\begin{array}{l}5.19 \\
(1.32)\end{array}$ & $0.59(0.001)$ & -2.00 & $0.047(-0.35,-0.00)$ & 183 \\
\hline Hours of work (1-7) & $\begin{array}{l}5.46 \\
(1.34)\end{array}$ & $0.53(0.001)$ & 0.99 & $0.325(-0.09,0.28)$ & 183 \\
\hline Remuneration (1-7) & $\begin{array}{l}4.60 \\
(1.48)\end{array}$ & $0.46(0.001)$ & -6.83 & $0.000(-0.96,-0.53)$ & 177 \\
\hline $\begin{array}{l}\text { Freedom to choose own working } \\
\text { method }(1-7)\end{array}$ & $\begin{array}{l}5.33 \\
(1.26)\end{array}$ & $0.53(0.001)$ & -0.36 & $0.720(-0.21,0.15)$ & 181 \\
\hline $\begin{array}{l}\text { Amount of responsibility given } \\
(1-7)\end{array}$ & $\begin{array}{l}5.07 \\
(1.39)\end{array}$ & $0.61(0.001)$ & -3.37 & $0.001(-0.47,-0.12)$ & 183 \\
\hline Recognition for good work (1-7) & $\begin{array}{l}4.83 \\
(1.52)\end{array}$ & $0.56(0.001)$ & -5.37 & $0.000(-0.71,-0.33)$ & 183 \\
\hline $\begin{array}{l}\text { Opportunity to use abilities } \\
(1-7)\end{array}$ & $\begin{array}{l}4.40 \\
(1.79)\end{array}$ & $0.67(0.001)$ & -9.77 & $0.000(-1.16,-0.77)$ & 182 \\
\hline Amount of variety in job (1-7) & $\begin{array}{l}4.52 \\
(1.81)\end{array}$ & $0.67(0.001)$ & -8.57 & $0.000(-1.04,-0.65)$ & 183 \\
\hline
\end{tabular}

\section{Table 2 Descriptive statistics}

\begin{tabular}{|c|c|c|c|c|c|}
\hline & Mean/\% & SD & Minimum & Maximum & $\mathrm{N}$ \\
\hline \multicolumn{6}{|l|}{ Personal and job characteristics } \\
\hline Gender female & $96.2 \%$ & - & 0 & 1 & 183 \\
\hline Age & 32.78 & 7.49 & 21.00 & 58.00 & 182 \\
\hline Years in current post & 2.81 & 2.80 & 0.08 & 16.33 & 174 \\
\hline Self-employed wholly/in part & $50.5 \%$ & - & 0 & 1 & 182 \\
\hline $\mathrm{N}$ patients per session & 6.45 & 2.45 & 1.20 & 21.83 & 171 \\
\hline Hours per week & 31.23 & 7.56 & 7.50 & 45.00 & 183 \\
\hline Salaried service wholly/in part & $21.2 \%$ & - & 0 & 1 & 183 \\
\hline \multicolumn{6}{|l|}{ Work assessments } \\
\hline Recognition from dentists (3-15) & 11.55 & 2.37 & 3 & 15 & 181 \\
\hline Recognition from patients (3-15) & 11.74 & 2.26 & 4 & 15 & 182 \\
\hline level of autonomous working (0-15) & 8.30 & 2.49 & 0 & 14 & 183 \\
\hline Hygiene work found rewarding (2-8) & 6.96 & 1.16 & 2 & 8 & 182 \\
\hline$\%$ clinical remit undertaken & 49.97 & 20.53 & 10.53 & 86.84 & 183 \\
\hline \multicolumn{6}{|c|}{ Satisfaction domains (four extrinsic and five intrinsic domains) } \\
\hline Colleagues and fellow workers (1-7) & 5.67 & 1.82 & 1 & 7 & 182 \\
\hline Physical working conditions (1-7) & 5.19 & 1.32 & 1 & 7 & 183 \\
\hline Hours of work (1-7) & 5.46 & 1.34 & 1 & 7 & 183 \\
\hline Remuneration (1-7) & 4.60 & 1.48 & 1 & 7 & 177 \\
\hline Freedom to choose own working method (1-7) & 5.33 & 1.26 & 2 & 7 & 181 \\
\hline Amount of responsibility given $(1-7)$ & 5.07 & 1.39 & 1 & 7 & 183 \\
\hline Recognition for good work (1-7) & 4.83 & 1.52 & 1 & 7 & 183 \\
\hline Opportunity to use abilities (1-7) & 4.40 & 1.79 & 1 & 7 & 182 \\
\hline Amount of variety in job (1-7) & 4.52 & 1.81 & 1 & 7 & 183 \\
\hline
\end{tabular}

worked abroad or exclusively in hospital, as tutors, in corporate bodies or the armed forces). Conversely, seven hygienists and two therapists who responded to the parallel surveys of those groups were found to have dual qualification, and are included here, giving a total of 183 respondents. Examination of data derived from the General Dental Council register found no response bias relating to gender, country, Strategic Health Authority or year of qualification (a proxy for age). The 14 sampled individuals with an additional qualification recorded (dental nurse or dental technician) had a significantly higher response rate (85\% cf 54\%, $X^{2}$ (Fisher's exact test $)=4.6$, $\mathrm{df}=1, \mathrm{p}=0.043)$.

A total of $95 \%$ of respondents (173) had qualified from a dual dental hygienetherapy course, the remainder having completed separate hygiene and therapy courses. Eighty-nine per cent (162) worked in England, 6\% (11) in Scotland, 4\% (8) in Wales and 1\% (2) in Northern Ireland. Three per cent (7) were male. The mean age was 32.78 years $(\mathrm{SD}=7.47)$, with only $15 \%$ aged 40 or above. Eighty-seven per cent (159) worked wholly or partly in the general dental service, mostly on a self-employed basis.

Mean score on overall satisfaction was 5.36 ( $\mathrm{SD}=1.28, \mathrm{n}=183$ ). Taking the recognised cut-off of 5 or more on the sevenpoint scale as indicating satisfaction, 75\% were satisfied with their job. However, there was considerable variation in overall satisfaction and in the nine satisfaction domains. Satisfaction was higher in relation to colleagues, and lower for remuneration, working conditions, recognition for good work, amount of responsibility, opportunity to use abilities, and variety of work (Table 1: significant differences ( $p<0.05$ ) in bold). These last four domains reflect aspects of intrinsic job satisfaction.

Table 2 shows the distributions of variables used in modelling overall job satisfaction, including the nine satisfaction domains. The 21 variables shown in Table 2 were entered into an initial multiple regression analysis with overall job satisfaction as the dependent variable. In order to limit the number of independent variables to a maximum of 18 , two background measures were dropped from further analysis: gender, being highly skewed (only seven were male); and age, which was restricted 


\begin{tabular}{|c|c|c|c|c|c|c|c|}
\hline & $\beta$ & $\mathrm{t}$ & $\mathrm{p}$ & & $\beta$ & $\mathrm{t}$ & $\mathrm{p}$ \\
\hline \multicolumn{8}{|l|}{ 1. Personal and job characteristics } \\
\hline Years in current post & 0.014 & 0.31 & 0.201 & Wholly self-employed & -0.105 & -2.06 & 0.041 \\
\hline$N$ patients per session & 0.062 & 1.34 & 0.181 & Hours per wk & -0.012 & -0.25 & 0.806 \\
\hline Salaried service & 0.041 & 0.84 & 0.400 & & & & \\
\hline \multicolumn{8}{|l|}{ 2. Work assessments } \\
\hline Recognition from dentists & 0.061 & 0.95 & 0.345 & Recognition from patients & 0.014 & 0.26 & 0.796 \\
\hline Level of autonomous working & -0.063 & -1.37 & 0.172 & Hygiene work found rewarding & 0.140 & 3.01 & 0.003 \\
\hline$\%$ clinical remit undertaken & 0.035 & 0.58 & 0.564 & & & & \\
\hline \multicolumn{8}{|l|}{ 3. Satisfaction domains } \\
\hline Colleagues and fellow workers & 0.196 & 3.00 & 0.003 & Physical working conditions & 0.120 & 1.94 & 0.055 \\
\hline Hours of work & 0.112 & 1.93 & 0.055 & Remuneration & 0.163 & 2.86 & 0.005 \\
\hline Freedom to choose working method & -0.034 & -0.51 & 0.609 & Amount of responsibility given & 0.052 & 0.72 & 0.472 \\
\hline Recognition for good work & 0.053 & 0.75 & 0.452 & Amount of variety in job & 0.343 & 5.26 & 0.000 \\
\hline
\end{tabular}

in range and had the largest p-value in the initial multiple regression. In addition, satisfaction with opportunity to use abilities and satisfaction with job variety were highly correlated $(\mathrm{r}=0.81)$, raising the possibility of model distortion through collinearity. After running the analysis first with one and then the other, satisfaction with opportunity to use abilities was dropped due to its smaller contribution to the model. Missing data were confirmed as missing completely at random by Little's test, and deleted pairwise.

Table 3 shows the result of the rerun analysis, with significant predictors $(p<0.05)$ shown in bold. The model explained $69 \%$ of the variance in overall job satisfaction. The second stage in the construction of the path model was the multiple regression modelling of the three satisfaction domains scores which predicted overall job satisfaction, using the variables listed in Table 3 under (1) personal and job characteristics and (2) work assessments. Finally, the three work assessment variables identified in the first or second stage were regressed by the personal and job characteristics variables. Figure 1 shows the resulting path diagram. The arrows are labelled with the beta weights (partial regression coefficients) which measure the extent of effect of one variable on another in the path model controlling for

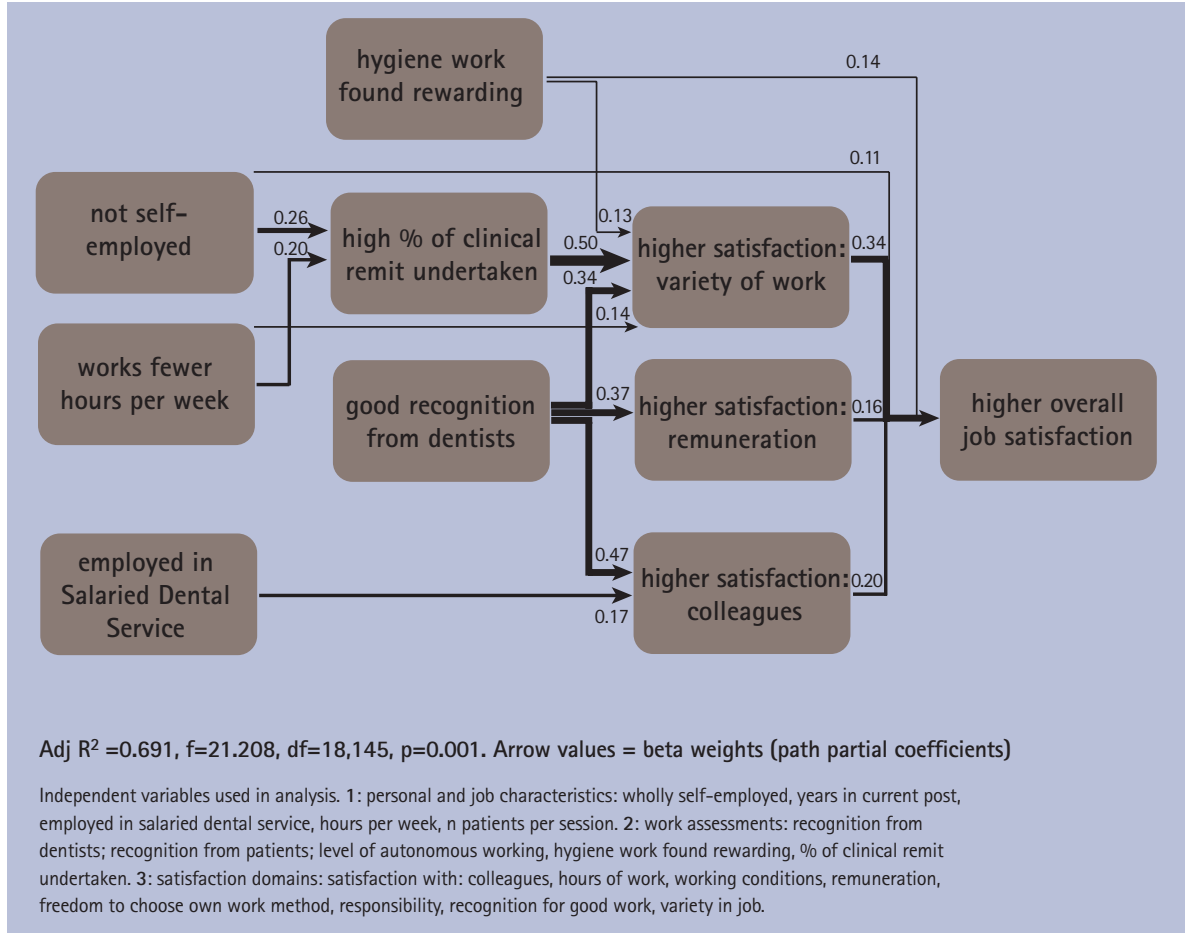

Fig. 1 Path diagram of overall job satisfaction

other prior variables. The strength of each association is also shown by the weight of the arrow.

The path analysis model shows higher satisfaction with variety of work to be the strongest direct predictor of higher overall job satisfaction. The strongest indirect predictor was the rating of dentists' recognition of qualification, quality of clinical work and clinical remit, which had strong associations with three satisfaction domains in the model. The sum of these paths $[(0.34 \times 0.34)+(0.37 \times 0.16)+(0$. $47 \times 0.20)$ ] indicates that this measure predicted $27 \%$ of the variance in overall job satisfaction.

The rating of the rewarding nature of hygiene work predicted $18 \%$ of overall satisfaction variance $[(0.13 \times 0.34)+0.14]$, while the measure of the extent to which 
the clinical remit was undertaken predicted $17 \%$ [0.50 x 0.34] through the indirect path via satisfaction with variety of work. Further light is cast on this relationship by respondents' classification of the 'skill mix' involved in their current clinical work as 'mostly using your hygienist skills', 'mostly using your therapist skills', or 'evenly split between the two'. They were then asked how they felt about this. Despite their dual qualification, the majority $(63 \%, \mathrm{n}=115$ ) described their skill mix as 'mostly using hygienist skills', 29\% (53) said it was an even split, and 8\% (15) said 'mostly using therapy skills'. The description of their skill mix as 'mainly hygiene' by the majority of the hygienist-therapists in the study is supported by the reported frequency in which clinical activities were undertaken. Figures $2 \mathrm{a}$ and $2 \mathrm{~b}$ show the contrast in eight clinical activities between (a) those who said they used therapist and hygienist skills equally or mostly used therapist skills ( $\mathrm{n}=68$ ), and (b) those who said they mostly used hygienist skills ( $\mathrm{n}=115$ ).

Open-ended comments on how hygienist-therapists felt about their skill mix indicated that many who reported that they mainly used hygienist skills were unhappy with the under-use of their therapy skills. Of those giving a comment, 24\% (23) said they were happy or 'OK' about mainly using hygienist skills, 44\% (43) said they would prefer more therapy but gave no further comment, and 32\% (30) added that they were not using their skills, or were frustrated, or otherwise felt negatively about it ( $n=96$, missing: 22 ). Only two of those who reported an even mix of therapy and hygiene or that their work was mainly therapy, said they would prefer a different mix of activities.

\section{DISCUSSION}

Some limitations to the use of the GDC register of DCPs as a sampling frame became apparent during the course of the study. Although all practising hygienist-therapists must be registered, alterations due to address changes or retirement depend on the registrant. A check on the registered details of 107 non-respondents 12 months after the fieldwork had ended revealed that $77 \%$ still had the same details as when the study sample was drawn, $22 \%$ had a new address, and $2 \%$ had left the register. It is possible therefore that the sampling frame

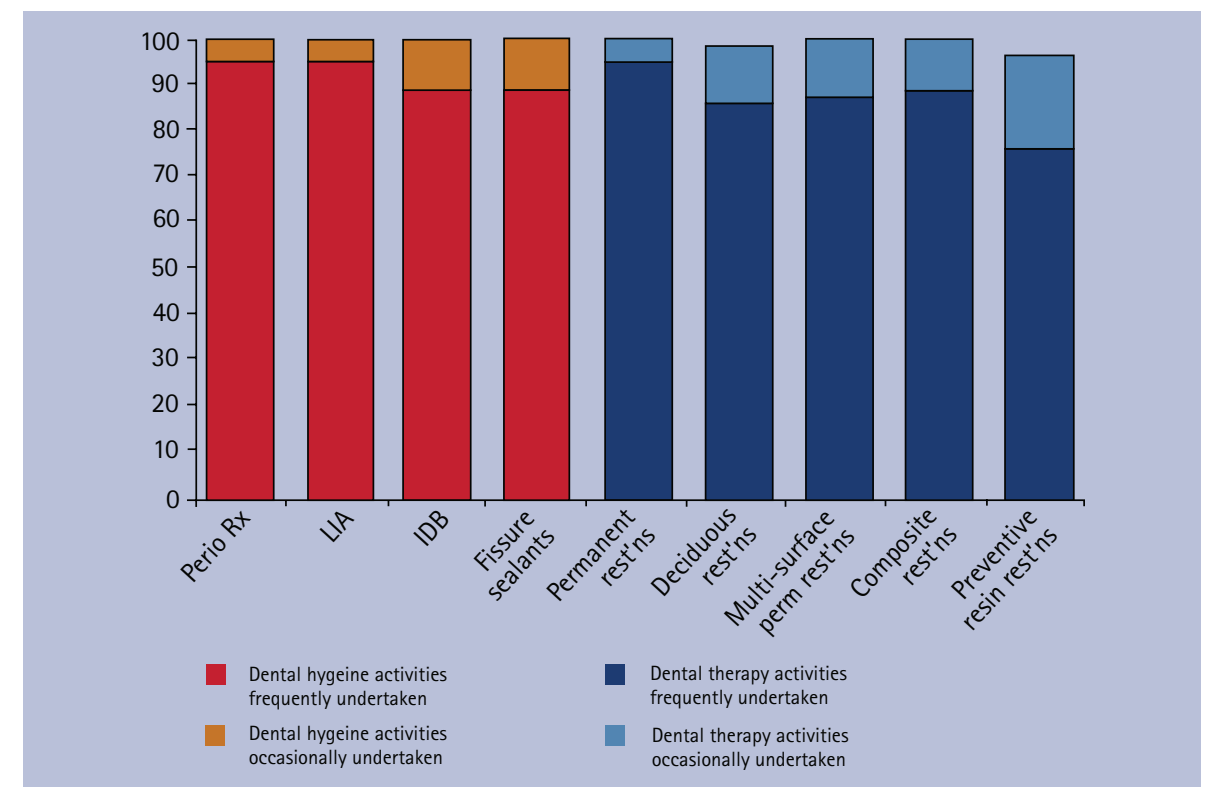

Fig. 2a \% hygienist-therapists reporting using both hygiene and therapy or mostly therapy skills by frequency in which clinical activities undertaken $(n=68)$.

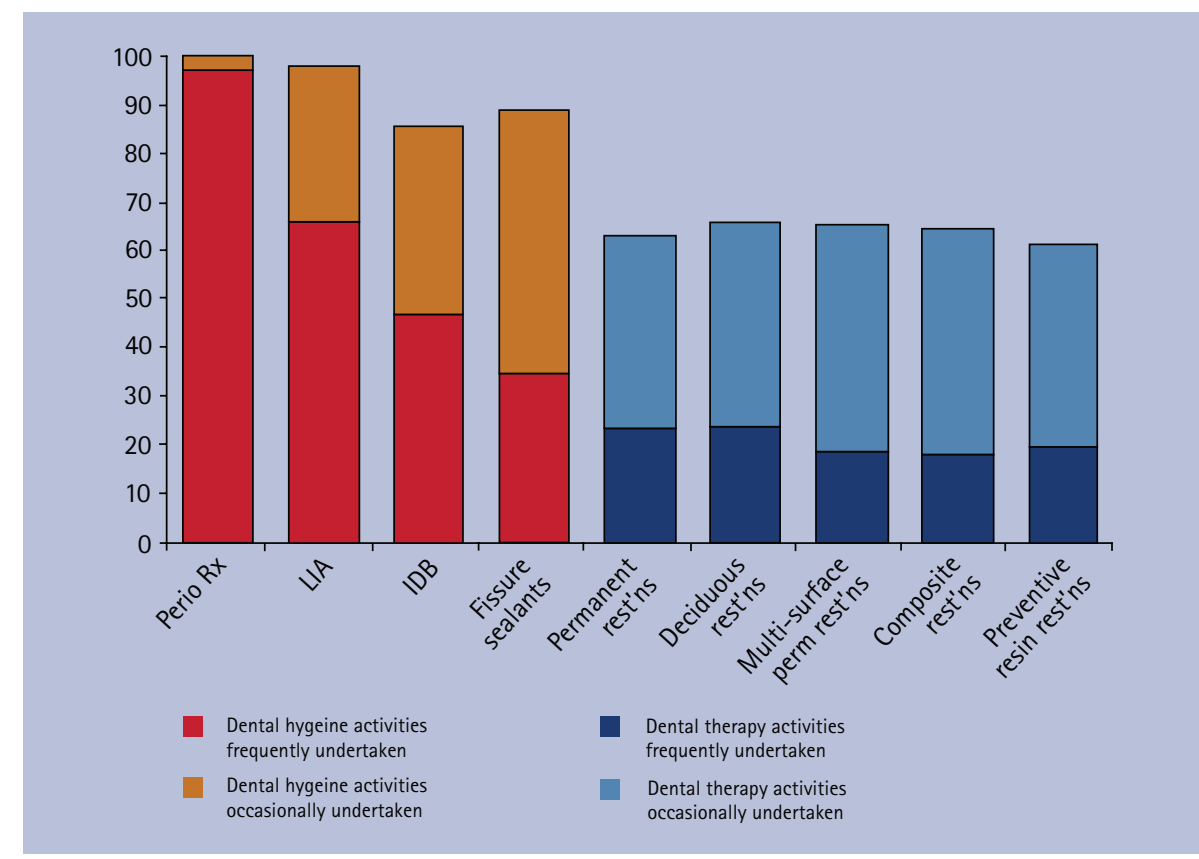

Fig. $2 \mathrm{~b} \%$ hygienist-therapists reporting using mostly hygiene skills by frequency in which clinical activities undertaken $(n=115)$

when used held inaccurate addresses for perhaps 5\% of the sample. In addition, it is likely that some hygienist-therapists maintain their registration with the GDC during periods when they are not practising (and therefore ineligible for the study), as there is an additional cost to re-registering after such a lapse. As hygienist-therapists are mainly 25 to 35 years of age it may be that, at any one time, a number will not be working due to maternity leave. (This limited age range may be why age was not found to be related to satisfaction, despite the established link between the two). ${ }^{14}$
The only way to accurately ascertain the numbers who had moved, retired or refused would be to telephone individuals or their practices. Given these considerations, we feel that the response rate of $60 \%$ is satisfactory.

Ten years ago there were few dually qualified hygienist-therapists in post, and dental therapists worked overwhelmingly in the salaried service, often part-time. The study suggests that by 2009 this situation had changed dramatically, with over $80 \%$ working in the General Dental Service and an average working week of over 30 hours. 
As a result many more are working as wholly and partly self-employed, often across several practices.

Overall satisfaction was high, with 75\% indicating they were satisfied with their job. Other research with dental care professionals has also reported high levels of overall job satisfaction. ${ }^{6}$ However, the present study found considerable variation across domains of job satisfaction, with remuneration, recognition for good work, amount of responsibility, opportunity to use abilities, variety of work and working conditions scoring low on this measure (Table 1).

The path analysis explained a high proportion (69\%) of the variance in overall job satisfaction through direct paths from five independent variables, with three being domains of job satisfaction. The most important direct predictor of overall job satisfaction, satisfaction with the variety of work, was strongly predicted by reported variety of clinical activity. The importance of attributes of the job in promoting job satisfaction is well established. ${ }^{15}$ In this study lack of variety was closely linked to lack of therapy activities, and was a source of disappointment and frustration for many. However, the finding that there was no direct path from percentage of clinical remit undertaken to overall satisfaction indicates that lack of therapy work in itself did not predict overall satisfaction; it was only when this lack of variety was judged unfavourably (that is, associated with lack of satisfaction with variety of work) that overall job satisfaction was adversely affected. Likewise the path model suggests that those hygienist-therapists who valued hygiene work highly were less concerned about any lack of therapy work, and tended to have higher overall job satisfaction as a result.

The most important indirect predictor was the rating of the recognition by dentists of good clinical work, clinical remit and qualification, which was a strong predictor of levels of satisfaction in three domains. This can be interpreted as a reflection of how hygienist-therapists in the study felt themselves to be valued by dental colleagues. Earlier work by the authors has shed light on this issue from the viewpoint of dentists and dental students, and has revealed misconceptions and negativity regarding the role and capability of DCPs., ${ }^{2,3}$ In a recent survey, 126 final-year dental students were asked to rank the importance of 12 overall influences on their long-term career. 'Teamwork' came last. When asked to rank 14 features perceived as enhancing the attractiveness of the NHS, the students placed 'teamwork' 12th. However, the authors noted that of the relatively small number who expected to become a primary dental care practitioner, most preferred to work in a 'team practice. ${ }^{16}$ Both recognition by colleagues and variety of work has been found to predict job satisfaction in studies of health service and other staff. ${ }^{17,18}$

The finding that many dually-qualified dental therapists are mainly working as hygienists is supported by evidence from other recent research. The situation is summed up by a recent NHS workforce review, which estimated that in England up to $80 \%$ practised solely as hygienists. ${ }^{19}$ The review nevertheless recommended that dual qualification and conversion courses should continue to expand in the place of single hygiene qualification courses, and concluded that this development 'offers the potential for a significant increase in the level and amount of primary dental care that can be offered to patients'.

Three recent studies investigated the clinical role of therapists. Godson et al. ${ }^{8}$ conducted a large-scale postal survey of therapists (both singly and dually qualified) in 2006. The authors report a higher level of therapy work than in the current study: for example, 81\% undertook deciduous pulpotomies, compared with $50 \%$ in the current study. This is likely to be a reflection of the inclusion of singly qualified therapists in the earlier study. Nevertheless, that study also reports dissatisfaction among dually qualified therapists with the lack of variety in their clinical work, usually in terms of a lack of therapy activities. ${ }^{8,20}$ A second study analysed day-book proformas from 209 therapists and hygienist-therapists. ${ }^{21}$ The authors conclude that dentists in the GDS were delegating a preventive role to hygienist-therapists which could equally be fulfilled by singly-qualified dental hygienists, thereby utilising only a small range of their skills. Two alternative solutions are suggested: meet the wishes of dentists by training more singly-qualified hygienists, or encourage dentists to use dental therapists/hygienist-therapists differently. The implications of the latter approach were investigated in a large scale case record review in 17 general dental practices. ${ }^{22}$ The authors conclude that if therapists undertook simple and intermediate restorative interventions, they could provide $43 \%$ of the total clinical time in these practices. Delegation of diagnostic and treatment planning powers to dental therapists could potentially increase this to $58 \%$ of clinical time.

Although overall job satisfaction appears high, this study suggests that dissatisfaction regarding certain aspects of their clinical work is widespread among duallyqualified dental therapists. Together, the path model and the direct comments of respondents confirm that lack of recognition and underuse of clinical skills are important issues, raising the danger of deskilling, demoralisation and possible loss of valuable members of the dental workforce. It is difficult to see how the NHS Workforce Planning Team's expectation that the growth in this profession will result in 'a significant increase' in the level of primary dental care without a more complete utilisation of the skills these practitioners possess. ${ }^{19}$

It has been argued that the future role of dentists should be as dental team leaders, with DCPs providing large elements of routine primary dental care, requiring service providers to employ more DCPs within a funded policy of extending teamworking. ${ }^{23}$ On the most basic level of numbers, this is still some way off. Currently the ratio of general dental practitioners to GDS-employed hygienists and hygienisttherapists is approximately 5:1, and while the present study found that most DCPs work in more than one practice, it is likely that many high street dental practices do not include even a part-time hygienist or hygienist-therapist in their clinical team. Provision also varies greatly between areas: according to the GDC Registrar, there is one dental hygienist-therapist for every 45,000 people in South Central England Strategic Health Authority (SHA), compared with one for every 182,000 in North East England SHA. The results of the 
present study suggest that more research needs to be undertaken to identify the barriers to and facilitators of genuine and widespread teamworking in dental primary care.

1. Harris R, Burnside G. The role of dental therapists working in four personal dental service pilots: type of patients seen, work undertaken and costeffectiveness within the context of the dental practice. Br Dent J 2004; 197: 491-496.

2. Csikar JI, Bradley S, Williams S A, Godson J H, Rowbotham J S. Dental therapy in the United Kingdom: part 4. Teamwork - is it working for dental therapists? Br Dent J 2009; 207: 529-536

3. Ross M K, Ibbetson R J, Turner S. The acceptability of dually-qualified dental hygienist-therapists to general dental practitioners in South-East Scotland. Br Dent J 2007; 202: E8.

4. Ross M K Turner S, Ibbetson R J. The impact of teamworking on the knowledge and attitudes of final year dental students. Br Dent J 2009; 206: 163-167.

5. Sprod A, Boyles J. The workforce of professionals complementary to dentistry in the general dental services: a survey of general dental practices in the South West. Br Dent J 2003; 194: 389-397.

6. Newton J T, Gibbons D E. Levels of career satisfaction among dental health care professionals: comparison of dental therapists, dental hygienists and dental practitioners. Community Dent Health
2001; 18: 172-176.

7. Gibbons D E, Corrigan M, Newton J T. The working practices and job satisfaction of dental therapists: findings of a national survey. Br Dent J 2000; 189: 435-438.

8. Lambert-Humble S. Opportunities for the dental team arising out of the new arrangements for primary dental care. Prim Dent Care 2005; 12: 15-19.

9. Shields M A, Ward M. Improving nurse retention in the National Health Service in England: the impact of job satisfaction on intentions to quit. J Health Econ 2001; 20: 677-701.

10. McColl E, Jacoby A, Thomas L et al. Design and use of questionnaires: a review of best practice applicable to surveys of health service staff and patients. Health Technology Assessment 2001; 5: 1-256.

11. Warr P, Cook J, Wall T. Scales for the measurement of some work attitudes and aspects of psychological well-being. J Occ Psych 1979; 52: 129-148.

12. Hair J F, Anderson R E, Tatham R L, Black W C. Multivariate data analysis. 5th ed. Upper Saddle River, New Jersey: Prentice Hall, 1998

13. Scott A, Gravelle H, Simoen S, Bojke C, Sibbald B. Job satisfaction and quitting intentions: a structural model of British general practitioners. Br J Ind Relat 2006; 44: 519-540.

14. Clarke A, Oswalde A, Warr P. Is job satisfaction U-shaped in age? J Occup Organ Psychol 1994 69: 57-81.

15. Hackman J R, Oldman G R. Motivation through the design of work: test of a theory. Organ Behav Hum Perform 1976; 16: 250-279.

16. Gallagher J, Patel R, Wilson N. The emerging dental workforce: long-term career expectations and influences. A quantitative study of final year dental students' views on their long-term career from one London Dental School. BMC Oral Health 2009; 9: 35 .

17. Lyons K J, Lapin J. Predictors of job satisfaction of nurses and allied health professionals. Health Policy Newsletter 2002; 15: Article 6. http://jdc.jefferson.edu/cgi/viewcontent. cgi?article=1271\&context=hpn. Accessed 11 January 2011.

18. Van Ham I, Verhoeven A A, Groenier K H, Groothoff $J$ W, De Haan J. Job satisfaction among general practitioners: a systematic literature review. Eur J Gen Pract 2006; 12: 174-180.

19. NHS Workforce Review Team. Workforce summary - dental therapists and dental hygienists 2008 England only. www.wrt.nhs.uk/index.php/work/ specs-profs/53-dentistry. Accessed 20/12/2009.

20. Csikar S, Godson J H, Williams S A, Bradley S, Rowbotham J S. Dental therapy in the United Kingdom: part 2. A survey of reported working practices. Br Dent J 2009; 207: 529-536.

21. Jones G, Evans C, Hunter L. A survey of the workload of dental therapists/hygienist-therapists employed in primary care settings. Br Dent J 2008; 204: E5.

22. Evans C, Chestnutt I G, Chadwick B L. The potential for delegation of clinical care in general dental practice. Br Dent J 2007; 203: 695-699.

23. Gallagher J, Wilson N. The future dental workforce? Br Dent J 2009; 206: 195-199. 